\title{
Sustainable Intensification in the Eastern Gangetic Plains: Key to Food Security and Livelihood Improvement of Smallholders ${ }^{\dagger}$
}

\author{
Thakur Tiwari 1,*, Mahesh Gathala ${ }^{2}$, Apurba Chowdhury ${ }^{3}$, Renuka Shrestha 4, Sanjay Kumar ${ }^{5}$, \\ Ujjwal Kumar 6, Saiful Islam ${ }^{2}$, Mamunur Rashid ${ }^{7}$, Mazharul Anwar ${ }^{8}$ and Illias Hossain ${ }^{9}$ \\ 1 International Maize and Wheat Improvement Centre, P.O. Box 5186, Kathmandu, Nepal \\ 2 International Maize and Wheat Improvement Centre, P.O. Box 6057, Dhaka 1213, Bangladesh; \\ m.gathala@cgiar.org (M.G.); ms.islam@cgiar.org (S.I.) \\ 3 Uttar Banga Krishi Vishowvidhyalaya, Cooch Behar, West Bengal 736165, India; apurba.patho@gmail.com \\ 4 Nepal Agriculture Research Council, Kathmandu 44600, Nepal; renuka.shrestha@gmail.com \\ 5 Agronomy Division, Bihar Agriculture University, Purnea, Sabour Bhagalpur, Bihar 813210, India; \\ skbau1612@gmail.com \\ 6 Indian Council of Agriculture Research, Patna, Bihar 800014, India; ujkumar19@gmail.com \\ 7 Rangpur Dinajpur Rural Services, Rangpur 5400, Bangladesh; mamunrdrs@gmail.com \\ 8 Bangladesh Agriculture Research Institute, Joydebpur, Gazipur 1701, Bangladesh; \\ anwar.sci.bari@gmail.com \\ 9 Bangladesh Wheat and Maize Research Institute, Rajshahi 1406, Bangladesh; iliasrwrc@gmail.com \\ * Correspondence: tiwaritp@hotmail.com \\ + Presented at the third International Tropical Agriculture Conference (TROPAG 2019), Brisbane, Australia, \\ 11-13 November 2019.
}

Published: 7 April 2020

\begin{abstract}
The Eastern Gangetic Plains (EGPs) has the potential to become a major contributor to South Asian regional food security, despite the world's highest concentration of rural poverty and a strong dependence on agriculture. A regional project entitled 'Sustainable and Resilient Farming Systems Intensification (SRFSI), managed by CIMMYT with over 20 partners with ACIAR/DFAT funding was launched in May 2014 to sustainably reduce the poverty. A total of 436 farmerparticipatory on-farm trials comparing the performance of three conservation agriculture based sustainable intensification (CASI) technologies like Zero/Strip till as base (ZT/ST) over the conventional tillage (CT; T1) practices were conducted across eight districts in northwest Bangladesh, Bihar and West Bengal in India, and eastern Terai of Nepal for two consecutive years i.e. 2015/16 and 2016/17. The three CASI treatments comprised a "partial CASI" option (T2: at least one crop in the cropping system established with ZT management) and two "full CASI" options (T3 and T4: all crops established with ZT/ST management; in T3 rice was direct seeded (DSR) while in T4, it was unpuddled transplanted (UPTR)). Multicriteria assessment showed an increase in rice equivalent system yield (RESY) by $4 \%$, gross margin by $19-20 \%$, input water productivity by $7-9 \%$ and energy productivity by $13-14 \%$ while decrease in requirements for irrigation water, energy, labor and the production cost by $15-17 \%, 10-11 \%, 32-38 \%$ and $15-18 \%$ respectively, and reduction in $\mathrm{CO}_{2}$ equivalent emission by $8-13 \%$ in full CASI over CT. CASI has shown great promise for food security and livelihood improvement at small scale.
\end{abstract}

Keywords: sustainability; intensification; conservation agriculture; cropping systems; emission; food security; livelihoods

(C) 2020 by the authors. Licensee MDPI, Basel, Switzerland. This article is an open access article distributed under the terms and conditions of the Creative Commons Attribution (CC BY) license (http://creativecommons.org/licenses/by/4.0/). 